\title{
Recognition of herpesviruses by the innate immune system
}

\author{
Søren R. Paludan ${ }^{1}$, Andrew G. Bowie ${ }^{2}$, Kristy A. Horan ${ }^{1}$, and Katherine A. Fitzgerald ${ }^{3}$ \\ ${ }^{1}$ Department of Medical Microbiology and Immunology, The Bartholin Building, Aarhus University, \\ DK-8000 Aarhus C, Denmark ${ }^{2}$ School of Biochemistry and Immunology, Trinity College Dublin, \\ Dublin 2, Ireland ${ }^{3}$ Division of Infectious Diseases and Immunology, University of Massachusetts \\ Medical School, Worcester, Massachusetts, USA
}

\begin{abstract}
Advances in innate immunity over the past decade have revealed distinct classes of pattern recognition receptors (PRRs) which operate to detect pathogens at the cell surface and in intracellular compartments. This has shed light on how herpesviruses, which are large diseasecausing DNA viruses that replicate in the nucleus, are initially recognized during cellular infection. Surprisingly, this involves multiple PRRs both on the cell surface, and within endosomes and the cytosol. In this article we describe recent advances in our understanding of innate detection of herpesviruses, how this innate detection translates into anti-herpesvirus host defense, and how the viruses seek to evade this innate detection to establish persistent infections.
\end{abstract}

Herpesviruses are a large family of DNA viruses. Among the known herpesviruses, eight can cause diseases in humans (Table 1), particularly in children and immunocompromised individuals ${ }^{1}$. Herpesviruses can be subdivided into the $a$-, $\beta$ - or $\gamma$-subfamilies based on their biological functions and sequence similarities (Table 1), but common to all herpesviruses is the ability to cause lytic infection in permissive cells, and to establish latency in specific specialized cell types (Box 1), such as neurons in the case of alphaherpesviruses, myeloid progenitors and/or lymphocytes in the case of betaherpesviruss, and lymphocytes in the case of gammaherpesviruses

Immunological control of herpesviruses is achieved by both the innate and adaptive immune system, with $\mathrm{CD}^{+} \mathrm{T}$ cells having a crucial role in the adaptive immune response ${ }^{2-5}$. In the innate antiviral immune response, type I interferons (IFNs) and natural killer (NK) cells have key roles in the containment of herpesvirus infections ${ }^{6-9}$. The innate immune system is activated following sensing of infections by pattern recognition receptors (PRRs) that detect pathogen-associated molecular patterns (PAMPs) ${ }^{10}$. Toll-like receptors (TLRs) are the first discovered and best characterized PRRs (Fig. 1). They are membrane-bound receptors localized in the plasma membrane and endosomal compartments. The TLRs in the plasma membrane generally recognize hydrophobic molecules such as lipids and proteins, whereas the endosomal TLRs sense nucleic acids ${ }^{10}$. More recently, intracellular PRRs have been identified that can detect pathogen nucleic acids in the cytoplasm. RNA is recognized by the retinoic acid-inducible gene I (RIG-I)-like receptors (RLRs) RIG-I and melanoma differentiation-associated gene 5 (MDA5), which detect $5^{\prime}$ triphosphate-panhandle RNA and higher order RNA structures, respectively ${ }^{11-13}$. Currently, five intracellular DNA sensing systems are known: DNA-dependent activator of IFN-regulatory factors (DAI) (also known as ZBP1), absent in melanoma 2 (AIM2), RNA polymerase III, leucine-rich repeat Flightless-interacting protein 1 (LLRFIP1) and most recently IFN $\gamma$-inducible protein 16 
(IFI16) ${ }^{14-22}$. With the exception of AIM2 (and under some circumstances RIG-I ${ }^{23}$ ), all TLRs and intracellular nucleic acid sensors induce intracellular signaling pathways that lead to the expression of genes with pro-inflammatory and microbicidal activities, including cytokines and type I IFNs (IFNa and IFN $\beta$ ) ${ }^{10,24}$. The stimulation of pro-inflammatory responses generally relies on activation of the transcription factors nuclear factor- $\mathrm{\kappa B}$ (NF$\kappa B$ ) and activator protein $1^{10,24}$, whereas the induction of IFNa expression depends on activation of the IFN regulatory factor (IRF) family and IFN $\beta$ expression requires IRFs and $\mathrm{NF}-\mathrm{\kappa B}^{25}$. By contrast, AIM2 activates the inflammasome, a large multiprotein complex that stimulates a proteolytic caspase-1-dependent pathway that cleaves pro-interleukin- $1 \beta$ (IL-1 $\beta$ ) and IL-18 into the mature bioactive pro-inflammatory cytokines ${ }^{15-18}$. Importantly, there is significant overlap between the downstream activities stimulated by PRRs so that some of pathways that lead to IFN activation also drive activation of other cytokines and cell death. For instance, IFI16 stimulates activation of both the IRF-3 and NF- $\kappa$ B pathways as well as caspase 2 and $3^{22,26}$.

For herpesviruses to establish infection, it is essential that they modulate host cells ${ }^{27}$ and evade host immune responses ${ }^{28-43}$. Evasion of the innate immune system may be particularly important for herpesviruses, given their slow replication cycle and maintenance of life-long latent infections. In this review we present the current knowledge on how the innate immune system detects herpesvirus infections, how this translates into antiviral immune responses, and how herpesviruses specifically evade this response, impacting on both primary infection and reactivation from latency.

\section{Recognition of herpesviruses by TLRs}

Substantial literature shows that TLRs can recognize herpesvirus PAMPs (Table 2, Fig. 1). This recognition controls cytokine and IFN expression in various cell types. The three classes of herpesvirus PAMPs recognized by TLRs are viral proteins, DNA and RNA.

\section{TLR2}

Following binding of herpesviruses to specific cellular receptors, the viral glycoprotein triade $\mathrm{gH}, \mathrm{gL}$ and $\mathrm{gB}$ mediate virion-cell lipid mixing, followed by full fusion of the virus and host cell membranes $44,45,46$. TLR2 on the plasma membrane, presumably in complex with TLR $1{ }^{47}$, recognizes herpesviruses through a process, which in the case of human cytomegalovirus (HCMV), that can be blocked by antibodies specific for $\mathrm{gB}$ and $\mathrm{gH}^{47-52}$. Exactly how herpesviruses stimulate TLR2 has not been elucidated, and in this respect it is also interesting that not all strains of HSV-1 activate TLR2 ${ }^{53}$. As TLR2 recognizes hydrophobic PAMPs, such as lipopeptides ${ }^{10,24}$, it is possible that TLR2 detects hydrophobic viral fusion peptides in $\mathrm{gH}$ and $\mathrm{gB}$, which are normally buried within the fusion proteins and only exposed during virus-cell membrane fusion. However, the available data do not exclude the possibility that TLR2 detects a lipid component exposed during viral entry. It should be mentioned that in the case of HSV-1, there is also evidence for innate immune recognition of viral glycoproteins independent of TLR2 ${ }^{54}$. TLR2 is expressed predominantly by myeloid cells, and has mainly been ascribed roles in the stimulation of inflammation ${ }^{10,24}$. During herpesvirus infections, TLR2 activation stimulates signaling that leads to NF- $\kappa$ B activation and expression of pro-inflammatory cytokines $49,51,52$, but it has recently been reported that the type I IFN response of inflammatory monocytes after infection with viruses, including MCMV, is partially dependent on TLR2 55 .

Mouse studies have shown both beneficial and deleterious roles for TLR2 in host defense against herpesviruses. Neonatal TLR2-deficient mice were protected against HSV-1 encephalitis following intraperitoneal infection, due to reduced inflammation rather than elevated viral load ${ }^{49}$. Subsequent studies have shown that TLR2 has protective roles in 
three models for HSV-2 and CMV infections. Mice lacking both TLR2 and TLR9 were significantly more susceptible to HSV-2 dissemination to the central nervous system than either TLR2-deficient or TLR9-deficient mice after intraperitoneal or intravaginal infection ${ }^{50}$, and TLR2-deficient mice had elevated levels of MCMV in the spleen and liver after intraperitoneal infection ${ }^{56}$. Both studies reported that a lack of TLR2 led to impaired expression of cytokines and activation of NK cells ${ }^{50,56}$, and it was demonstrated that MCMV-induced production of type I IFNs was compromised in TLR2-deficient mice 56 . Two genetic studies in humans have now shown that TLR2 has protective roles during natural herpesvirus infections. TLR2 haplotypes 2 and 4 were shown to be associated with increased frequency of genital HSV-2 lesions and viral shedding in infected individuals ${ }^{57}$, and transplant recipients with the TLR2 polymorphism R753Q have elevated HCMV replication and are more likely to develop CMV disease ${ }^{58}$. Both of these studies addressed the role of TLR2 in established infection, and thus suggest that TLR2 is involved in controlling herpesviruses in the latent state.

\section{TLR9}

The most potent immune-stimulating component of herpesvirus particles is probably the genomic DNA. TLR9 senses DNA in endosomes ${ }^{59}$, and all three classes of human herpesviruses are recognized by TLR9 ${ }^{60-64}$. In addition, MCMV and murine gammaherpesvirus 68 (MHV68) are recognized by this PRR, allowing pathogenesis studies in animal models ${ }^{65-67}$. Based on studies using synthetic DNA, the prevailing paradigm has been that TLR9 recognizes CpG motif-containing DNA, which is abundantly present in herpesvirus genomes. Recent studies on natural DNA suggest that both $\mathrm{CpG}$ content and the level of methylation of the motif strongly affects the ability of DNA to activate TLR9 ${ }^{68}$, whereas the DNA sugar backbone 2' deoxyribose rather than the CpG motif determines TLR9 activation by synthetic DNA ${ }^{69}$. Thus, the molecular mechanism of TLR9-mediated sensing of herpesvirus DNA remains to be fully understood. In humans, TLR9 expression is restricted to B cells and plasmacytoid DCs (pDCs), whereas in mice it is widely expressed by many cell types ${ }^{10,24}$. As TLR9 signaling leads to the activation of IRF $7{ }^{70}$, recognition of herpesviruses by TLR9 by both human and mouse pDCs leads to the expression of type I IFNs $60,61,63,71$.

Initial studies on herpesvirus infections in TLR9-deficient mice failed to demonstrate a phenotype ${ }^{61}$. Subsequently, modest effects of TLR9 deficiency on early antiviral and inflammatory events after HSV infections have been reported, mainly due to impaired pDCderived type I IFN response in the TLR9-deficient mice and impaired NK cell activation $^{50,72-74}$. Importantly, in a model of corneal HSV-1 infection a more pronounced phenotype was observed in TLR9-deficient mice with significantly compromised expression of ISGs, recruitment of neutrophils and control of viral load ${ }^{75}$. In the MCMV model, infection of TLR9-deficient mice through the intraperitoneal route revealed an impaired antiviral response and increased mortality. TLR9 was shown to stimulate early type I IFN production as well as NK cell production of IFN $\gamma^{71}$. Other groups have confirmed the role of TLR9 in the early type I IFN response, and demonstrated the source to be pDCs 76,77 . Finally, TLR9-deficiency has also been reported to impair the host response to MHV68 infection with reduced cytokine expression by DCs and higher viral load during both during lytic and latent infection by mice lacking TLR9 ${ }^{67}$. With respect to $\gamma$-herpesviruses it has been demonstrated TLR9 has essential roles in eliminating the acute MHV68 infection and controlling latent viral load ${ }^{67}$, following infection through the intraperitoneal but not intranasal route. Therefore, TLR9 is important for the host response only to pathogens that reach locations where pDCs are abundantly present (such as the lymphoid organs and the blood stream). The specialized but often redundant role of TLR9 in the protective immune response to herpesvirus infections is further supported by the observation that patients with 
an IL-1R-associated kinase 4 (IRAK4) mutation, and hence abolished IFN production by TLR7, TLR8 and TLR9, do not have increased susceptibility to infections with herpesviruses ${ }^{78}$.

\section{TLR3}

While TLR2 and TLR9 are activated by PAMPs present in the herpesvirus particle, replication of herpesviruses leads to the intracellular accumulation of double-stranded RNA (dsRNA) structures ${ }^{79}$, which can function as TLR3 agonists ${ }^{80}$. Although the specific RNA species of $a$ - and $\beta$-herpesviruses that stimulate TLR3 have not been characterized, latencyassociated EBV-encoded small RNAs (EBERs), which are nonpolyadenylated, noncoding dsRNAs stem-loop structures, have been reported to be released from EBV-infected cells and to stimulate TLR3 ${ }^{81}$.

TLR3 is constitutively expressed by several cell types including epithelial cells and CD8 $a^{+}$ DCs. In addition, TLR3 expression is strongly induced by type I IFNs and viral infections in most cell types ${ }^{82}$. TLR3 signaling through the adaptor protein TIR-domain-containing adaptor protein inducing IFN $\beta$ (TRIF) potently activates IRF3 and NF- $\kappa B$, leading to the expression of IFN $\beta$ and other pro-inflammatory cytokines ${ }^{83}$. The specific expression of TLR3 by CD8 $a^{+}$DCs promotes the cross-presentation of viral antigens ${ }^{84}$, which contributes to development of an efficient $\mathrm{CD} 8^{+} \mathrm{T}$ cell response against HSV-1 ${ }^{85}$. Currently it is not known how herpesvirus RNA that accumulates in the cytoplasm is detected by endosomal TLR3. This may involve phagocytosis of infected cells in the case of CD8 $a^{+}$ DCs ${ }^{84}$, but it is less obvious what happens in stromal cells, where for example autophagy may be used to traffic this viral danger signal to TLR3-containing compartments.

MCMV-infected TLR3-deficient mice have increased viral loads in the spleen and reduced serum cytokine levels, but show no difference in survival compared with wild-type mice ${ }^{65}$. In addition, it was recently shown that TLR3-deficient mice exhibit impaired generation of virus-specific $\mathrm{CD}^{+} \mathrm{T}$ cells following skin HSV-1 infection, which was associated with impaired control of the virus at late time points post infection ${ }^{85}$, suggesting a role for TLR3 in stimulation of the adaptive immune response, as previously proposed ${ }^{84}$. The most compelling evidence for a role for TLR3 in host defense against herpesvirus infections stems from the identification of a rare TLR3 P554S homozygous mutant in two children with HSV-1 encephalitis but absent in more than 1,500 healthy controls ${ }^{86}$. Fibroblasts from these patients responded to HSV-1 infection with an impaired IFN $\beta$ response ${ }^{86}$. Finally, a recent case report describes the L412F TLR3 gene variant, which encodes a receptor with reduced activity ${ }^{87}$, in a patient with frequently recurrent lymphocytic HSV-2 meningitis ${ }^{88}$. Despite these data, the mechanism by which TLR3 exerts protective roles against HSV infection in the central nervous system is unknown.

\section{TLR7}

In addition to TLR3, TLR7, a single-stranded RNA sensor expressed by $\mathrm{pDCs}^{76}$, has recently been reported to sense MCMV infection, and this recognition is essential for a full IFNa response and optimal antiviral defense ${ }^{76}$. TLR7xTLR9 double-deficient mice are significantly more susceptible to MCMV infection than either of the single knockout mice strains ${ }^{76}$, and comparable to mice lacking the TLR adaptor proteins myeloid differentiation primary-response protein 88 (MyD88). Since both $\alpha$ - and $\beta$-herpesvirus particles have been reported to contain viral mRNAs ${ }^{89,90}$, it is not clear whether TLR7 senses virion- or replication-associated RNA.

Collectively, herpesviruses are detected by TLR2, 3, 7, and 9. While TLR3, 7, and 9 detect herpesvirus nucleic acids,TLR2 senses virions, although we still lack full understanding of 
the nature of the PAMP. All together, TLR-mediated sensing of herpesviruses orchestrates early antiviral and inflammatory responses.

\section{Recognition of herpesviruses by intracellular nucleic acid receptors}

Although TLRs have a clear role in the sensing of herpesvirus infections, the fact that viruses replicate and persist intracellularly suggested that PRRs operating in the intracellular environment to detect viral RNA and DNA PAMPs also contribute to innate immune recognition of these viruses ${ }^{91}$.

RNA

Intracellular herpesvirus RNA can be recognized by the RLRs. Similar to TLR3, RIG-I senses EBERs, but it does so in the cytoplasm, leading to induction of both IFNs and the cytokine IL-10 ${ }^{92,93}$. We have recently reported that HSV-1-induced IFN responses by primary human monocyte-derived macrophages depend on MDA5 and its adaptor protein mitochondrial antiviral signaling protein (MAVS; also known as CARDIF, IPS1 and VISA) ${ }^{35,94}$. As the response was also dependent on viral gene expression, which correlated with the induction of IFNs and IFN-stimulated genes (ISGs), these data suggest that replication-induced higher-order RNA structures are detected by MDA5 in HSV-1-infected human macrophages ${ }^{35,94}$. In contrast to most TLRs, the RLRs are expressed by most cells in the body, and are also strongly induced by IFNs ${ }^{95}$. Therefore, RLRs could be involved in the recognition of herpesvirus infection in permissive cells, particularly at later stages of infection when the expression of RLRs will be strongly upregulated. In such a scenario, RLRs would not be responsible for the initial antiviral IFN response, but instead contribute to the control of productive infections.

\section{DNA}

Given that herpesviruses have DNA genomes, the main focus of the search for host intracellular sensing systems has been on viral DNA recognition. Akira and colleagues first reported that transfection of HSV and HCMV DNA into fibroblasts induces TLRindependent expression of IFN $\beta^{96}$. We subsequently reported that expression of type I IFNs by splenic conventional DCs was independent of TLR9, but dependent on viral entry and genomic DNA ${ }^{72}$. The first cytoplasmic DNA sensor to be identified was the ISG DAI, which induces signaling to activate IRF3 and induce type I IFN expression ${ }^{14}$, and the initial report indicated a role for DAI in HSV-1-induced IFN $\beta$ expression ${ }^{14}$. However, this was seen only in a murine fibroblast-like cell line ${ }^{14}$, and subsequent analysis of DAI-deficient mice has failed to identify any essential roles for DAI in innate antiviral responses ${ }^{97}$. Based on this, it seems that DAI is not the main sensor of at least HSV DNA, and indicates a more specialized role for DAI, which remains to be described. Interestingly, recent studies show that type I IFN expression by HCMV-infected fibroblasts is mediated by DAI ${ }^{98,99}$, which suggests a role for DAI in the early response to herpesvirus infections in a specific subset of cells.

Although the RLRs are sensors of RNA, some data have suggested a role for this system in the detection of DNA ${ }^{100}$. Two reports have now provided a potential mechanism. AT-rich DNA can be transcribed by RNA polymerase III into 5'-triphosphate RNA, which subsequently activates RIG-I. This pathway was reported to be involved in type I IFN induction during EBV infections where EBERs are transcribed by RNA polymerase III ${ }^{19}$. This indirect DNA-sensing system was also reported to be involved in induction of type I IFNs following HSV-1 infection ${ }^{20}$. However, other studies have not been able to demonstrate a role for RNA polymerase III in sensing of HSV-1 DNA ${ }^{22,94}$, and one report has shown direct interaction between HSV-1 DNA and RIG-I and non-redundant roles for 
RIG-I and MDA5 in HSV DNA sensing in fibroblasts ${ }^{101}$. These findings raise questions as to the requirement for RNA polymerase III in herpesvirus DNA recognition, and urge for identification of the potential mechanism involved. RLRs belong to the family of $\mathrm{DExD} / \mathrm{H}$ box helicases (DHX), and two other members of this family, namely DHX9 and DHX36, have recently been reported to recognize CpG-DNA in pDCs and induce activation of NF$\mathrm{B}$ and IRF7, respectively, via MyD88 ${ }^{102}$. Importantly, DHX9 and DHX36 were associated with the expression of pro-inflammatory cytokines and IFNa, respectively, after HSV-1 infection in a human pDC line ${ }^{102}$. The proposal that DHX9 and DHX36 are novel sensors of cytosolic DNA in pDCs may explain previously unexplained findings of TLR9independent cytokine responses to HSV and CMV infections in pDCs ${ }^{72,77,103}$.

Herpesviruses are also known to activate inflammasomes leading to caspase-1 activation. The identification of AIM2 as a cytosolic dsDNA sensor stimulating caspase-1 activation has provided a mechanism for this 16-18,104. AIM2 belongs to the PYHIN (pyrin and HIN domain-containing protein) family and binds DNA through its HIN domain. AIM2 then engages apoptosis-associated speck-like protein containing a CARD (ASC; also known as PYCARD) via pyrin domain interactions and recruits pro-caspase-1, leading to the production of active caspase- 1 and mature IL- $1 \beta$ and IL-18. There is genetic evidence demonstrating that the AIM2 inflammasome is activated by MCMV ${ }^{105}$, and MCMVinfected AIM2-deficient mice exhibit reduced levels of serum IL-18 and spleen IFN $\gamma$ production as well as elevated viral load ${ }^{105}$. By contrast, the inflammasome activated by HSV-1 appears to be independent of AIM2 and remains to be further characterized ${ }^{105}$.

Recently, in a collaborative effort between our laboratories, we identified IFI16, another PYHIN family protein, as an intracellular sensor of HSV-1 DNA, stimulating the expression of IFN $\beta$ and pro-inflammatory genes during infection with this virus ${ }^{22}$. Free HSV-1 genomic DNA was found in the cytosol during infection and IFI16 bound directly to isolated viral DNA motifs. Reduction in the expression of IFI16, or its mouse ortholog p204, by RNA interference inhibited DNA- and HSV-1-mediated gene induction and activation of IRF3 and NF- $\kappa \mathrm{B}{ }^{22}$. Although IFI16 is mainly present in the nucleus, a significant portion localizes to the cytosol, where it co-localizes with viral DNA ${ }^{22}$. However, it remains possible that IFI16 recognizes HSV-1 DNA in the nucleus and migrates to the cytoplasm to stimulate signal transduction. Together with AIM2 and p202 (a PYHIN protein that negatively regulates AIM2), these proteins constitute a new family of AIM2-like receptors (ALR)s that recognize intracellular DNA. The role of IFI16 in innate antiviral defense against herpesviruses in vivo remains to be described, including its role in directing adaptive immune responses. As MCMV and HCMV exploit IFI16 for their own benefit to promote replication ${ }^{29,106}$, it will be interesting to determine if the net effect of herpesvirus-IFI16 interactions are beneficial or detrimental for the ability of herpesviruses to replicate.

In summary, intracellular nucleic acid-sensing PRRs have an important role in the activation of innate immune responses against viruses. In the case of herpesviruses, RNA replication intermediates can stimulate endosomal and cytosolic PRRs, but it seems that the genomic DNA is the main trigger of the innate immune response. In the case of recognition of RNA viruses by RLRs, it was recently reported that genomic RNA generated by viral replication constitutes the major trigger for RLRs ${ }^{107}$. Based on the available data on herpesvirus recognition, and the observation that herpesvirus DNA replication occurs after innate immune activation is initiated, it seems for DNA viruses it is the incoming genomic material that is sensed by PRRs.

\section{Exposure of herpesvirus DNA PAMPs to intracellular PRRs}

Despite the identification of several PRRs capable of recognizing herpesvirus nucleic acid PAMPs, it is not known how the genomic material arrives at these cellular compartments, 
and how the capsid-protected DNA is made accessible to PRRs. Herpesviruses can enter cells through both endocytic and non-endocytic pathways ${ }^{44}$. Following endocytic entry, endosomal processing of viral capsids can potentially lead to the exposure of viral DNA and presentation to TLR9 (Fig. 2). After entry through the non-endocytic pathway, where TLR9 stimulation also occurs ${ }^{72}$, alternative pathways of viral delivery to endosomes must be involved. This could involve autophagy, in parallel to the reported role for autophagy in delivering cytosolic viral RNA to TLR7 in endosomes ${ }^{108}$.

We recently demonstrated that HSV-1 DNA can be detected in the cytosol of infected cells ${ }^{22}$. However, whether DNA in the cytosol originates from the nuclear, cytoplasmic or endosomal compartments is still unclear. Viruses entering through an endocytic route ${ }^{44}$, may be subject to degradation which could be followed by translocation of DNA PAMPs from the endosomal lumen to the cytosol. Alternatively, herpesvirus DNA may be exposed to the cytosol following proteasomal degradation of the viral capsid. Proteasomal activity is essential for induction of ISGs during HSV infection and for the delivery of HSV DNA from the capsid to the nucleus 109,110 . Thus, there are many potential mechanisms that may mediate the exposure of herpesvirus DNA to the cytosolic DNA sensing machinery, all requiring further examination. Herpesvirus replication occurs in the nucleus of infected cells, potentially providing an abundance of DNA for recognition at this location. However, at present there is no evidence for innate immune sensing by herpesviruses in the nucleus, although the localization of IFI16 to both the cytosol and nucleus is intriguing and urges for investigation of its potential role in the recognition of herpesvirus DNA in the nucleus.

\section{Activation of signal transduction in response to intracellular DNA sensing}

Cytosolic DNA recognition leads to the activation of TANK-binding kinase 1 (TBK1), IRF3, and the production of type I IFNs and pro-inflammatory cytokines (Fig. 2). However, the signaling pathway linking upstream DNA sensors to TBK1 are poorly characterized. TBK1 associates with DDX3, a DEAD box RNA helicase, which regulates IFN $\beta$ transcription by IRF3 $99,111,112$. In addition, TBK1 interacts with the exocyst protein Sec5 in a complex that includes the recently identified endoplasmic reticulum (ER) adaptor stimulator of IFN genes (STING) ${ }^{113}$, although the role of Sec5 in this complex is unclear. STING is essential for activation of the signaling pathway upstream of TBK1 following HSV-1 infection 113,114 and has been shown to associate with IFI16, and to relay signals downstream of DAI ${ }^{22,99}$. STING interacts with the ER translocon components Sec61 $\beta$ and TrapB in a manner that is essential for regulation of cytosolic DNA-induced type I IFN production ${ }^{113}$, although the mechanism involved is not known.

Concerning the subcellular location where cytosolic STING-dependent DNA- signaling occurs, recent studies have provided interesting, but somewhat contradictory conclusions. In unstimulated cells, STING localizes to the ER and perhaps ER-associated mitochondria $22,99,115$. Following stimulation with cytosolic DNA and HSV-1 STING translocates to perinuclear foci, via the Golgi $22,99,115$. However, the nature of these STINGcontaining structures is contentious. One report indicates that STING localizes partially to endosomes, particularly Sec5-positive structures ${ }^{114}$, whereas another report has shown that STING localizes to vesicular structures, which are not peroxisomes, mitochondria, endosomes or autophagosomes ${ }^{115}$. Clearly, further work is required to elucidate the composition and sites of signaling in response to intracellular DNA recognition.

\section{Evasion of innate immune responses by herpesviruses}

Herpesviruses are large viruses, with slow replication cycles and the ability to establish latent infections. Initiation of replication and establishment of infection is heavily influenced by the early virus-host interactions occurring within minutes of exposure, including 
hijacking of preexisting host cell signaling pathways (e.g. phosphoinositide-3-kinase/ AKT) ${ }^{27}$. Therefore, to successfully colonize the host, herpesviruses need to actively evade and modulate host responses at all stages of infection. There is strong evidence for herpesviruses evading the innate immune system ${ }^{28-43}$ (Fig. 3). This includes avoidance of sensing by PRRs, blocking of the action of PRRs, and inhibition of signaling pathways and gene expression. With respect to evasion of recognition, the HSV-1-encoded RNA endonuclease virion host shut-off protein (vhs), an mRNA-specific RNase that cleaves virus and host mRNA ${ }^{116}$, was recently reported to impair activation of the RNA-sensing pathways through TLR3 and RLRs in conventional DCs, presumably by destroying the viral agonists that trigger this response ${ }^{30}$. Likewise, HSV-1 counteracts delivery of PAMPs from the cytoplasm to endosomal compartments where TLR3, 7, and 9 operate ${ }^{117}$. The neurovirulence factor ICP34.5 prevents autophagy by directly binding to the autophagyinducing protein Beclin $1{ }^{34}$. Given the reported role for autophagy in delivery of viral cargo to endosomal TLRs ${ }^{108}$, the ICP34.5-mediated inhibition of autophagy is likely to counteract detection of viral nucleic acids by endosomal TLRs.

The second principle in innate immune evasion is inhibition of the action of specific PRRs. For instance, the HSV immediate-early protein ICP0 inhibits TLR2 responses by promoting degradation of MyD88 and MyD88-adaptor-like (MAL; also known as TIRAP) ${ }^{33}$.

Following the recent identification of cytosolic DNA sensors proposed to be involved in stimulation of innate immune responses during herpesvirus infections $14,19,20,22,102$, it is interesting that there is now evidence for herpesvirus proteins inhibiting both DAI, DHX9, and IFI16 29,31,37. The HCMV tegument protein pUL83, which has long been known to inhibit virus-induced expression of ISGs ${ }^{118,119}$, has been identified to directly interacts with IFI16, suggesting an immune evasion strategy whereby HCMV could inhibit IFI16dependent antiviral responses ${ }^{29}$. In support of this idea, the guinea pig CMV UL83 deletion mutant virus is significantly attenuated in vivo ${ }^{120}$. Likewise, MCMV targets DAI signaling via its M45 protein ${ }^{31}$, and the HHV8 protein kinase directly interacts with DHX9 and inhibits downstream activities of the receptor ${ }^{37}$. All together, these data suggest a very important role for the intracellular DNA sensors in the innate immune response to herpesviruses.

The third principle in innate immune evasion involves viral inhibition of downstream signaling and gene expression programs activated by PRRs. Given the important role for type I IFNs in innate antiviral defense to herpesviruses $6,7,121$, it is no surprise that all classes of herpesviruses target the IRF-IFN pathway at various levels $28,32,35,36,38-40,42,43$ (Fig. 3). The E3 ubiquitin ligase ICP0 of HSV-1 and other a-herpesviruses can inhibit nuclear accumulation of IRF3 and induction of IFN ${ }^{28,122}$. At the mechanistic level, this involves both degradation of IRF-3 and sequestration of IRF-3 and CBP/p300, which is dependent on cytoplasmic localization of ICP0 $28,123,124$. While most herpesvirus immune evasion proteins share limited homology with the proteins they antagonize, the HHV8 genome contains a cluster of open reading frames encoding proteins with homology to the IRF family ${ }^{40}$, vIRFs, which inhibit expression of IFNs. For instance, vIRF3 inhibits the action of IRF3, 5 , and 7 by directly interacting with the cellular IRFs, hence preventing DNA binding and IFN promoter activation ${ }^{125,126}$. Collectively, herpesviruses target the innate immune system by avoiding sensing by PRRs, blocking the action of specifically PRRs, and inhibiting signaling pathways and expression of antiviral genes. The identification of such viral immune evasion strategies provides strong evidence for the importance of the early innate immune system in control of herpesvirus infections. 


\section{Role for the innate immune system in latent herpesvirus infections}

Latent herpesvirus infections are characterized by the presence of viral DNA in the nucleus of infected cells, but limited or no viral replication activities. It has long been known that $\mathrm{CD}^{+} \mathrm{T}$ cells are important for controlling herpesvirus infections during latency and reactivation ${ }^{2,3}$, but emerging evidence suggests that the innate branch of the immune system also has a central role in controlling latent herpesvirus infections. For instance, pDCs infiltrate the dermis of recurrent genital HSV-2 lesions and stimulate T cell proliferation ${ }^{127}$. Interestingly, the cells in the dermis immediately surrounding the pDCs were positive for ISGs, suggesting a role for type I IFNs in controlling recurrent HSV-2 infection. This is further supported by the ability of HSV-1 ICP0, which is a rate-limiting protein in reactivation of a-herpesviruses, to inhibit IRF3 activation and IFN production ${ }^{28}$. Although the role of ICP0 in reactivation was originally believed to be due to its role in replication, this may also be attributed to the essential role of ICP0 in limiting the host IFN response, a function now also ascribed to the HHV8 latency-associated nuclear antigen $1^{42}$. Finally, one of the reported patients with the TLR3 P554S mutation developed HSV encephalitis during both primary and recurrent infection, further suggesting a role for the innate immune system in controlling herpesviruses in the latent state ${ }^{86}$.

The innate immune system may affect herpesvirus latency at various steps. The classical innate antiviral activity of type I IFNs during primary infection may reduce the latent viral genome load per cell as suggested from mouse studies 67,128 . Second, IFNs could be induced during reactivation, as indicated by the expression of ISGs during HSV-2 reactivation ${ }^{127}$. This would suggest that PRRs, such as ALRs, sense low-grade reactivation or even the latent viral genome. Third, the ability of the innate immune response to shape the adaptive immune response could affect the potency of the $\mathrm{CD} 8^{+} \mathrm{T}$ cell response. In this respect it is worth noting that TLR3-deficient mice exhibit impaired development of virus-specific CD8 ${ }^{+}$ $\mathrm{T}$ cells in a model for HSV-1 skin infection ${ }^{85}$.

Further support for a role of the innate immune system in controlling herpesviruses comes from evidence that TLRs are exploited by these viruses for both establishment of latency and reactivation. Establishment of latency by MHV68 has been reported to be impaired in MyD88-deficient mice, probably due to reduced activation of B cells, which are the main latency reservoir ${ }^{129}$, suggesting that MHV68 uses TLR signaling to condition the target cell for establishment of latency. In addition, two studies have shown that TLR stimulation of cells latently infected with MHV68 or HHV8 reactivates these two $\gamma$-herpesviruses ${ }^{130,131}$. For HHV8 infection, it was further demonstrated that not only synthetic PAMPs but also infection with vesicular stomatitis virus, which stimulates TLR7 and RIG-I, led to reactivation of the infection ${ }^{130}$. These findings demonstrate that secondary pathogen infection can reactivate HHV8 through stimulation of PRRs.

\section{Conclusions and perspectives}

Our understanding of how herpesviruses are detected by the innate immune system and stimulate antiviral activities has grown tremendously over the past decade. This has been accompanied by an increased understanding of how these viruses evade the innate immune response and establish persistent infection. This field now faces several interesting questions that need to be addressed to achieve the knowledge required for translation of basic knowledge into understanding of disease pathogenesis. First, with the identification of new intracellular PRRs that sense herpesvirus infections, it is essential to establish their roles and mechanisms of action in immune defense and pathogenesis. Given the important role of ALRs in the recognition of herpesviruses, understanding the intracellular dynamics of recognition and signaling molecules, and also how the viral DNA is made accessible for 
PRRs is essential. Progress in this area may also start to resolve the important question of whether herpesviruses are detected by the innate immune system in the nucleus, and if this is the case, how viral DNA is then distinguished from host DNA.

Second, while it is clear that detection of classical PAMPs is central to immune surveillance, we also believe that the innate immune system can sense viral infections through other mechanisms. It seems likely that novel principles of pathogen recognition remain to be discovered, by which viral activities rather than molecular structures are sensed. This would allow the host to distinguish pathogenic from non-pathogenic infections. Lytic infection, a property of all herpesviruses, is an activity directly associated with pathogenicity, and a recent report has shown that $2^{\prime} 5^{\prime}$ oligoadenylate synthetase is induced in virus-infected cells, released following cell lysis and subsequently taken up by non-infected cells to exert antiviral activity ${ }^{132}$. It will be interesting to establish if host sensing of pathogen-induced processes is a whole new layer of immune surveillance yet to be described.

Third, herpesviruses, and in particular EBV, have been proposed to be involved in the pathogenesis of autoimmune diseases 133,134 . Given the overlap between PRRs that recognize herpesviruses, most notably TLR9 and IFI16, and those proposed to be involved in the pathogenesis of autoimmune diseases such as systemic lupus erythematosus, Sjogren syndrome, and systemic sclerosis ${ }^{135-137}$, the role of herpesviruses and PRRs in these conditions should be explored further to potentially identify the long-sought-after missing link between herpesviruses and autoimmune diseases. Finally, although the intellectual and experimental forefront of immunology research has always been centered on studies in rodents, it is important that the findings from these model studies are tested in human systems. Moreover, a close interaction between the basic and clinical research communities will reassure that new discoveries are rapidly investigated under conditions of direct relevance for diseases caused by herpesviruses in humans. The identification of several novel primary immunodeficiencies with defects in viral sensing and type I IFN production, all of which are associated with susceptibility to HSV encephalitis $6,86,138,139$, underscores the important role of the innate immune system in controlling herpesvirus infections, and maintaining the balance between the virus and the host achieved through millions of years of co-evolution.

\section{Acknowledgments}

This work was supported by grants from The Danish Medical Research Council (09-072636), The Lundbeck Foundation (R34-A3855), Velux Fonden, Kathrine og Vigo Skovgaards Fond, and Elvira og Rasmus Riisforts almenvelgørende Fond (awarded to SRP), by grants from the NIH (AI067497, AI64349, AI083713 and AI079293) awarded to KAF and by grants from Science Foundation Ireland to AGB. KAH was supported by a Marie Curie Incoming International Fellowship.

\section{References}

1. Pellett, PE.; Roizman, B. Fields Virology. Lippincort, Williams, Wilkins; Philadelphia: 2007. The Family: Herpesviridae A brief introduction; p. 2579-2500.

2. Liu T, Khanna KM, Chen X, Fink DJ, Hendricks RL. CD8(+) T cells can block herpes simplex virus type 1 (HSV-1) reactivation from latency in sensory neurons. J Exp Med. 2000; 191:14591466. [PubMed: 10790421]

3. Liu T, Khanna KM, Carriere BN, Hendricks RL. Gamma interferon can prevent herpes simplex virus type 1 reactivation from latency in sensory neurons. J Virol. 2001; 75:11178-11184. [PubMed: 11602757]

4. Reusser P, Riddell SR, Meyers JD, Greenberg PD. Cytotoxic T-lymphocyte response to cytomegalovirus after human allogeneic bone marrow transplantation: pattern of recovery and correlation with cytomegalovirus infection and disease. Blood. 1991; 78:1373-1380. [PubMed: 1652311] 
5. Braaten DC, Sparks-Thissen RL, Kreher S, Speck SH, Virgin HW. An optimized CD8+ T-cell response controls productive and latent gammaherpesvirus infection. J Virol. 2005; 79:2573-2583. [PubMed: 15681457]

6. Dupuis S, et al. Impaired response to interferon-alpha/beta and lethal viral disease in human STAT1 deficiency. Nat Genet. 2003; 33:388-391. This paper showed that patients with STAT1 deficiency do not respond to type I IFNs and are susceptible to herpes simplex encephalitis. [PubMed: 12590259]

7. Salazar-Mather TP, Lewis CA, Biron CA. Type I interferons regulate inflammatory cell trafficking and macrophage inflammatory protein 1alpha delivery to the liver. J Clin Invest. 2002; 110:321330. [PubMed: 12163451]

8. Biron CA, Byron KS, Sullivan JL. Severe herpesvirus infections in an adolescent without natural killer cells. N Engl J Med. 1989; 320:1731-1735. [PubMed: 2543925]

9. Rager-Zisman B, Quan PC, Rosner M, Moller JR, Bloom BR. Role of NK cells in protection of mice against herpes simplex virus-1 infection. J Immunol. 1987; 138:884-888. [PubMed: 3805719]

10. Takeuchi O, Akira S. Pattern recognition receptors and inflammation. Cell. 2010; 140:805-820. [PubMed: 20303872]

11. Schlee M, et al. Recognition of 5' triphosphate by RIG-I helicase requires short blunt doublestranded RNA as contained in panhandle of negative-strand virus. Immunity. 2009; 31:25-34. [PubMed: 19576794]

12. Schmidt A, et al. 5'-triphosphate RNA requires base-paired structures to activate antiviral signaling via RIG-I. Proc Natl Acad Sci U S A. 2009; 106:12067-12072. [PubMed: 19574455]

13. Pichlmair A, et al. Activation of MDA5 requires higher-order RNA structures generated during virus infection. J Virol. 2009; 83:10761-10769. [PubMed: 19656871]

14. Takaoka A, et al. DAI (DLM-1/ZBP1) is a cytosolic DNA sensor and an activator of innate immune response. Nature. 2007; 448:501-505. DAI was the first cytoplasmic DNA sensor to be identified, and was shown to contribute to the type I IFN response to HSV-1 infection. [PubMed: 17618271]

15. Hornung V, et al. AIM2 recognizes cytosolic dsDNA and forms a caspase-1-activating inflammasome with ASC. Nature. 2009; 458:514-518. [PubMed: 19158675]

16. Burckstummer T, et al. An orthogonal proteomic-genomic screen identifies AIM2 as a cytoplasmic DNA sensor for the inflammasome. Nat Immunol. 2009; 10:266-272. [PubMed: 19158679]

17. Fernandes-Alnemri T, Yu JW, Datta P, Wu J, Alnemri ES. AIM2 activates the inflammasome and cell death in response to cytoplasmic DNA. Nature. 2009; 458:509-513. [PubMed: 19158676]

18. Roberts TL, et al. HIN-200 proteins regulate caspase activation in response to foreign cytoplasmic DNA. Science. 2009; 323:1057-1060. [PubMed: 19131592]

19. Ablasser A, et al. RIG-I-dependent sensing of poly(dA:dT) through the induction of an RNA polymerase III-transcribed RNA intermediate. Nat Immunol. 2009; 10:1065-1072. [PubMed: 19609254]

20. Chiu YH, Macmillan JB, Chen ZJ. RNA Polymerase III Detects Cytosolic DNA and Induces Type I Interferons through the RIG-I Pathway. Cell. 2009; 138:576-591. [PubMed: 19631370]

21. Yang P, et al. The cytosolic nucleic acid sensor LRRFIP1 mediates the production of type I interferon via a beta-catenin-dependent pathway. Nat Immunol. 2010; 11:487-494. [PubMed: 20453844]

22. Unterholzner L, et al. IFI16 is an innate immune sensor for intracellular DNA. Nat Immunol. 2010; 11:997-1004. This paper identifies IFI16 as an intracellular sensor of DNA, which is essential for the IFN and cytokine response to HSV-1 infection, and the work is also the first to demonstrate the presence free viral genomic DNA in the cytoplasm during infection. [PubMed: 20890285]

23. Poeck H, et al. Recognition of RNA virus by RIG-I results in activation of CARD9 and inflammasome signaling for interleukin 1 beta production. Nat Immunol. 2010; 11:63-69. [PubMed: 19915568]

24. Mogensen TH. Pathogen recognition and inflammatory signaling in innate immune defenses. Clin Microbiol Rev. 2009; 22:240-273. [PubMed: 19366914]

25. Honda K, Taniguchi T. IRFs: master regulators of signalling by Toll-like receptors and cytosolic pattern-recognition receptors. Nat Rev Immunol. 2006; 6:644-658. [PubMed: 16932750] 
26. Gugliesi F, et al. The proapoptotic activity of the Interferon-inducible gene IFI16 provides new insights into its etiopathogenetic role in autoimmunity. J Autoimmun. 2010; 35:114-123. [PubMed: 20488664]

27. Chandran B. Early events in Kaposi's sarcoma-associated herpesvirus infection of target cells. J Virol. 2010; 84:2188-2199. [PubMed: 19923183]

28. Melroe GT, DeLuca NA, Knipe DM. Herpes simplex virus 1 has multiple mechanisms for blocking virus-induced interferon production. J Virol. 2004; 78:8411-8420. [PubMed: 15280450]

29. Cristea IM, et al. Human Cytomegalovirus pUL83 Stimulates Activity of the Viral ImmediateEarly Promoter through its Interaction with the Cellular IFI16 Protein. J Virol. 2010; 84:78037814. [PubMed: 20504932]

30. Cotter CR, et al. The virion host shut-off (vhs) protein blocks a TLR-independent pathway of herpes simplex virus type 1 recognition in human and mouse dendritic cells. PLoS One. 2010; 5:e8684. [PubMed: 20174621]

31. Rebsamen M, et al. DAI/ZBP1 recruits RIP1 and RIP3 through RIP homotypic interaction motifs to activate NF-kappaB. EMBO Rep. 2009; 10:916-922. [PubMed: 19590578]

32. Wu L, et al. Epstein-Barr virus LF2: an antagonist to type I interferon. J Virol. 2009; 83:11401146. [PubMed: 18987133]

33. van Lint AL, et al. Herpes Simplex Virus Immediate-Early ICP0 Protein Inhibits TLR2-dependent Inflammatory Responses and NF-\{kappa\}B Signaling. J Virol. 2010; 84:10802-10811. [PubMed: 20686034]

34. Orvedahl A, et al. HSV-1 ICP34.5 confers neurovirulence by targeting the Beclin 1 autophagy protein. Cell Host Microbe. 2007; 1:23-35. [PubMed: 18005679]

35. Melchjorsen J, Siren J, Julkunen I, Paludan SR, Matikainen S. Induction of cytokine expression by herpes simplex virus in human monocyte-derived macrophages and dendritic cells is dependent on virus replication and is counteracted by ICP27 targeting NF-kappaB and IRF-3. J Gen Virol. 2006; 87:1099-1108. [PubMed: 16603509]

36. Verpooten D, Ma Y, Hou S, Yan Z, He B. Control of TANK-binding kinase 1-mediated signaling by the gamma(1)34.5 protein of herpes simplex virus 1. J Biol Chem. 2009; 284:1097-1105. [PubMed: 19010780]

37. Jong JE, Park J, Kim S, Seo T. Kaposi's sarcoma-associated herpesvirus viral protein kinase interacts with RNA helicase a and regulates host gene expression. J Microbiol. 2010; 48:206-212. [PubMed: 20437153]

38. Zhu FX, King SM, Smith EJ, Levy DE, Yuan YA. Kaposi's sarcoma-associated herpesviral protein inhibits virus-mediated induction of type I interferon by blocking IRF-7 phosphorylation and nuclear accumulation. Proc Natl Acad Sci U S A. 2002; 99:5573-5578. [PubMed: 11943871]

39. Jaworska J, Gravel A, Fink K, Grandvaux N, Flamand L. Inhibition of transcription of the beta interferon gene by the human herpesvirus 6 immediate-early 1 protein. J Virol. 2007; 81:57375748. [PubMed: 17376932]

40. Lubyova B, Pitha PM. Characterization of a novel human herpesvirus 8-encoded protein, vIRF-3, that shows homology to viral and cellular interferon regulatory factors. J Virol. 2000; 74:81948201. [PubMed: 10933732]

41. Taylor RT, Bresnahan WA. Human cytomegalovirus IE86 attenuates virus- and tumor necrosis factor alpha-induced NFkappaB-dependent gene expression. J Virol. 2006; 80:10763-10771. [PubMed: 17041226]

42. Cloutier N, Flamand L. Kaposi sarcoma-associated herpesvirus latency-associated nuclear antigen inhibits interferon (IFN) beta expression by competing with IFN regulatory factor-3 for binding to IFNB promoter. J Biol Chem. 2010; 285:7208-7221. [PubMed: 20048166]

43. Sen N, et al. Varicella Zoster Virus Immediate Early Protein 62 Blocks IRF3 Phosphorylation at Key Serine Residues: A Novel Mechanism of IRF3 Inhibition among Herpesviruses. J Virol. 2010; 84:9240-9253. [PubMed: 20631144]

44. Akhtar J, Shukla D. Viral entry mechanisms: cellular and viral mediators of herpes simplex virus entry. FEBS J. 2009; 276:7228-7236. [PubMed: 19878306] 
45. Subramanian RP, Geraghty RJ. Herpes simplex virus type 1 mediates fusion through a hemifusion intermediate by sequential activity of glycoproteins D, H, L, and B. Proc Natl Acad Sci U S A. 2007; 104:2903-2908. [PubMed: 17299053]

46. Atanasiu D, Saw WT, Cohen GH, Eisenberg RJ. Cascade of events governing cell-cell fusion induced by herpes simplex virus glycoproteins gD, gH/gL, and gB. J Virol. 2010; 84:1229212299. [PubMed: 20861251]

47. Boehme KW, Guerrero M, Compton T. Human Cytomegalovirus Envelope Glycoproteins B and H Are Necessary for TLR2 Activation in Permissive Cells. J Immunol. 2006; 177:7094-7102. [PubMed: 17082626]

48. Compton T, et al. Human cytomegalovirus activates inflammatory cytokine responses via CD14 and Toll-like receptor 2. J Virol. 2003; 77:4588-4596. This paper is the first to identify a TLR involved in the recognition of a herpesvirus. [PubMed: 12663765]

49. Kurt-Jones EA, et al. Herpes simplex virus 1 interaction with Toll-like receptor 2 contributes to lethal encephalitis. Proc Natl Acad Sci U S A. 2004; 101:1315-1320. [PubMed: 14739339]

50. Sorensen LN, et al. TLR2 and TLR9 synergistically control herpes simplex virus infection in the brain. J Immunol. 2008; 181:8604-8612. [PubMed: 19050280]

51. Wang JP, et al. Varicella-zoster virus activates inflammatory cytokines in human monocytes and macrophages via Toll-like receptor 2. J Virol. 2005; 79:12658-12666. [PubMed: 16188968]

52. Gaudreault E, Fiola S, Olivier M, Gosselin J. Epstein-Barr virus induces MCP-1 secretion by human monocytes via TLR2. J Virol. 2007; 81:8016-8024. [PubMed: 17522215]

53. Sato A, Linehan MM, Iwasaki A. Dual recognition of herpes simplex viruses by TLR 2 and TLR9 in dendritic cells. Proc Natl Acad Sci U S A. 2006; 103:17343-17348. [PubMed: 17085599]

54. Reske A, Pollara G, Krummenacher C, Katz DR, Chain BM. Glycoprotein-dependent and TLR2independent innate immune recognition of herpes simplex virus-1 by dendritic cells. J Immunol. 2008; 180:7525-7536. [PubMed: 18490753]

55. Barbalat R, Lau L, Locksley RM, Barton GM. Toll-like receptor 2 on inflammatory monocytes induces type I interferon in response to viral but not bacterial ligands. Nat Immunol. 2009; 10:1200-1207. [PubMed: 19801985]

56. Szomolanyi-Tsuda E, Liang X, Welsh RM, Kurt-Jones EA, Finberg RW. Role for TLR2 in NK cell-mediated control of murine cytomegalovirus in vivo. J Virol. 2006; 80:4286-4291. [PubMed: 16611887]

57. Bochud PY, Magaret AS, Koelle DM, Aderem A, Wald A. Polymorphisms in TLR2 are associated with increased viral shedding and lesional rate in patients with genital herpes simplex virus Type 2 infection. J Infect Dis. 2007; 196:505-509. [PubMed: 17624834]

58. Kijpittayarit S, Eid AJ, Brown RA, Paya CV, Razonable RR. Relationship between Toll-like receptor 2 polymorphism and cytomegalovirus disease after liver transplantation. Clin Infect Dis. 2007; 44:1315-1320. [PubMed: 17443468]

59. Ahmad-Nejad P, et al. Bacterial CpG-DNA and lipopolysaccharides activate Toll-like receptors at distinct cellular compartments. Eur J Immunol. 2002; 32:1958-1968. [PubMed: 12115616]

60. Lund J, Sato A, Akira S, Medzhitov R, Iwasaki A. Toll-like receptor 9-mediated recognition of Herpes simplex virus-2 by plasmacytoid dendritic cells. J Exp Med. 2003; 198:513-520. This paper is the first to identify a TLR involved in the recognition of herpesvirus nucleic acids. [PubMed: 12900525]

61. Krug A, et al. Herpes simplex virus type 1 activates murine natural interferon-producing cells through toll-like receptor 9. Blood. 2004; 103:1433-1437. [PubMed: 14563635]

62. Varani S, et al. Human cytomegalovirus differentially controls B cell and T cell responses through effects on plasmacytoid dendritic cells. J Immunol. 2007; 179:7767-7776. [PubMed: 18025223]

63. Lim WH, Kireta S, Russ GR, Coates PT. Human plasmacytoid dendritic cells regulate immune responses to Epstein-Barr virus (EBV) infection and delay EBV-related mortality in humanized NOD-SCID mice. Blood. 2007; 109:1043-1050. [PubMed: 17018863]

64. Fiola S, Gosselin D, Takada K, Gosselin J. TLR9 Contributes to the Recognition of EBV by Primary Monocytes and Plasmacytoid Dendritic Cells. J Immunol. 2010; 185:3620-3631. [PubMed: 20713890] 
65. Tabeta K, et al. Toll-like receptors 9 and 3 as essential components of innate immune defense against mouse cytomegalovirus infection. Proc Natl Acad Sci U S A. 2004; 101:3516-3521. [PubMed: 14993594]

66. Krug A, et al. TLR9-dependent recognition of MCMV by IPC and DC generates coordinated cytokine responses that activate antiviral NK cell function. Immunity. 2004; 21:107-119. [PubMed: 15345224]

67. Guggemoos S, et al. TLR9 contributes to antiviral immunity during gammaherpesvirus infection. J Immunol. 2008; 180:438-443. [PubMed: 18097045]

68. Yasuda K, et al. Requirement for DNA CpG content in TLR9-dependent dendritic cell activation induced by DNA-containing immune complexes. J Immunol. 2009; 183:3109-3117. [PubMed: 19648272]

69. Haas T, et al. The DNA sugar backbone 2' deoxyribose determines toll-like receptor 9 activation. Immunity. 2008; 28:315-323. [PubMed: 18342006]

70. Honda K, et al. IRF-7 is the master regulator of type-I interferon-dependent immune responses. Nature. 2005; 434:772-777. [PubMed: 15800576]

71. Delale T, et al. MyD88-dependent and -independent murine cytomegalovirus sensing for IFNalpha release and initiation of immune responses in vivo. J Immunol. 2005; 175:6723-6732. [PubMed: 16272328]

72. Rasmussen SB, et al. Type I IFN production during HSV infection is controlled by cell-type specific viral recognition by TLR9, the mitochondrial antiviral signaling protein pathway, and novel recognition systems. J Virol. 2007; 81:13315-13324. [PubMed: 17913820]

73. Sarangi PP, Kim B, Kurt-Jones E, Rouse BT. Innate recognition network driving herpes simplex virus-induced corneal immunopathology: role of the toll pathway in early inflammatory events in stromal keratitis. J Virol. 2007; 81:11128-11138. [PubMed: 17686871]

74. Lund JM, Linehan MM, Iijima N, Iwasaki A. Cutting Edge: Plasmacytoid dendritic cells provide innate immune protection against mucosal viral infection in situ. J Immunol. 2006; 177:75107514. [PubMed: 17114418]

75. Wuest T, et al. Intact TRL 9 and type I interferon signaling pathways are required to augment HSV-1 induced corneal CXCL9 and CXCL10. J Neuroimmunol. 2006; 179:46-52. [PubMed: 16884784]

76. Zucchini N, et al. Cutting edge: Overlapping functions of TLR7 and TLR9 for innate defense against a herpesvirus infection. J Immunol. 2008; 180:5799-5803. [PubMed: 18424698]

77. Hokeness-Antonelli KL, Crane MJ, Dragoi AM, Chu WM, Salazar-Mather TP. IFN-alphabetamediated inflammatory responses and antiviral defense in liver is TLR9-independent but MyD88dependent during murine cytomegalovirus infection. J Immunol. 2007; 179:6176-6183. [PubMed: 17947693]

78. $\mathrm{Ku} \mathrm{CL}$, et al. Selective predisposition to bacterial infections in IRAK-4-deficient children: IRAK-4-dependent TLRs are otherwise redundant in protective immunity. J Exp Med. 2007; 204:2407-2422. [PubMed: 17893200]

79. Weber F, Wagner V, Rasmussen SB, Hartmann R, Paludan SR. Double-stranded RNA is produced by positive-strand RNA viruses and DNA viruses but not in detectable amounts by negative-strand RNA viruses. J Virol. 2006; 80:5059-5064. This report showed that double-stranded RNA accumulates in the cytoplasm of permissive cells infected with HSV-1. [PubMed: 16641297]

80. Alexopoulou L, Holt AC, Medzhitov R, Flavell RA. Recognition of double-stranded RNA and activation of NF-kappaB by Toll- like receptor 3. Nature. 2001; 413:732-738. [PubMed: 11607032]

81. Iwakiri D, et al. Epstein-Barr virus (EBV)-encoded small RNA is released from EBV-infected cells and activates signaling from Toll-like receptor 3. J Exp Med. 2009; 206:2091-2099. [PubMed: 19720839]

82. Miettinen M, Sareneva T, Julkunen I, Matikainen S. IFNs activate toll-like receptor gene expression in viral infections. Genes Immun. 2001; 2:349-355. [PubMed: 11607792]

83. Yamamoto M, et al. Role of adaptor TRIF in the MyD88-independent toll-like receptor signaling pathway. Science. 2003; 301:640-643. [PubMed: 12855817] 
84. Schulz O, et al. Toll-like receptor 3 promotes cross-priming to virus-infected cells. Nature. 2005; 433:887-892. [PubMed: 15711573]

85. Davey GM, et al. Cutting edge: priming of CD8 T cell immunity to herpes simplex virus type 1 requires cognate TLR3 expression in vivo. J Immunol. 2010; 184:2243-2246. [PubMed: 20124105]

86. Zhang SY, et al. TLR3 deficiency in patients with herpes simplex encephalitis. Science. 2007; 317:1522-1527. This study showed that patients with TLR3-decifiency exhibit impaired IFN response to HSV-1 infection in vitro and susceptibility to herpes simplex encephalitis. [PubMed: 17872438]

87. Ranjith-Kumar CT, et al. Effects of single nucleotide polymorphisms on Toll-like receptor 3 activity and expression in cultured cells. J Biol Chem. 2007; 282:17696-17705. [PubMed: 17434873]

88. Willmann O, Ahmad-Nejad P, Neumaier M, Hennerici MG, Fatar M. Toll-like receptor 3 immune deficiency may be causative for HSV-2-associated mollaret meningitis. Eur Neurol. 2010; 63:249251. [PubMed: 20375513]

89. Sciortino MT, Suzuki M, Taddeo B, Roizman B. Rnas extracted from herpes simplex virus 1 virions: apparent selectivity of viral but not cellular rnas packaged in virions. J Virol. 2001; 75:8105-8116. [PubMed: 11483756]

90. Bresnahan WA, Shenk T. A subset of viral transcripts packaged within human cytomegalovirus particles. Science. 2000; 288:2373-2376. [PubMed: 10875924]

91. Malmgaard L, Melchjorsen J, Bowie AG, Mogensen SC, Paludan SR. Viral activation of macrophages through TLR-dependent and -independent pathways. J Immunol. 2004; 173:68906898. [PubMed: 15557184]

92. Samanta M, Iwakiri D, Kanda T, Imaizumi T, Takada K. EB virus-encoded RNAs are recognized by RIG-I and activate signaling to induce type I IFN. EMBO J. 2006; 25:4207-4214. [PubMed: 16946700]

93. Samanta M, Iwakiri D, Takada K. Epstein-Barr virus-encoded small RNA induces IL-10 through RIG-I-mediated IRF-3 signaling. Oncogene. 2008; 27:4150-4160. [PubMed: 18362887]

94. Melchjorsen J, et al. Innate recognition of HSV in human primary macrophages is mediated via the MDA5/MAVS pathway and MDA5/MAVS/Pol III independent pathways. J Virol. 2010; 84:11350-11358. [PubMed: 20739519]

95. Yoneyama M, et al. The RNA helicase RIG-I has an essential function in double-stranded RNAinduced innate antiviral responses. Nat Immunol. 2004; 5:730-737. [PubMed: 15208624]

96. Ishii KJ, et al. A Toll-like receptor-independent antiviral response induced by double-stranded Bform DNA. Nat Immunol. 2006; 7:40-48. This paper was the first to report that herpesvirus DNA (HSV and HCMV) has the capacity to stimulate innate immune responses through cytosolic PRRs. [PubMed: 16286919]

97. Ishii KJ, et al. TANK-binding kinase-1 delineates innate and adaptive immune responses to DNA vaccines. Nature. 2008; 451:725-729. [PubMed: 18256672]

98. Defilippis VR, et al. Activation of the Interferon Response by Human Cytomegalovirus Occurs via Cytoplasmic Double-Stranded DNA but Not Glycoprotein B. J Virol. 2010; 84:8913-8925. [PubMed: 20573816]

99. Defilippis VR, Alvarado D, Sali T, Rothenburg S, Fruh K. Human Cytomegalovirus Induces the Interferon Response Via the DNA Sensor ZBP1. J Virol. 2010; 84:585-598. [PubMed: 19846511]

100. Cheng G, Zhong J, Chung J, Chisari FV. Double-stranded DNA and double-stranded RNA induce a common antiviral signaling pathway in human cells. Proc Natl Acad Sci U S A. 2007; 104:9035-9040. [PubMed: 17517627]

101. Choi MK, et al. A selective contribution of the RIG-I-like receptor pathway to type I interferon responses activated by cytosolic DNA. Proc Natl Acad Sci U S A. 2009; 106:17870-17875. [PubMed: 19805092]

102. Kim T, et al. Aspartate-glutamate-alanine-histidine box motif (DEAH)/RNA helicase A helicases sense microbial DNA in human plasmacytoid dendritic cells. Proc Natl Acad Sci U S A. 2010; 107:15181-15186. [PubMed: 20696886] 
103. Prebeck S, et al. Predominant role of toll-like receptor 2 versus 4 in Chlamydia pneumoniaeinduced activation of dendritic cells. J Immunol. 2001; 167:3316-3323. [PubMed: 11544320]

104. Pichyangkul S, et al. Malaria blood stage parasites activate human plasmacytoid dendritic cells and murine dendritic cells through a Toll-like receptor 9-dependent pathway. J Immunol. 2004; 172:4926-4933. [PubMed: 15067072]

105. Rathinam VA, et al. The AIM2 inflammasome is essential for host defense against cytosolic bacteria and DNA viruses. Nat Immunol. 2010; 11:395-402. This work is the first to demonstrate an essential role for a cytoplasmic DNA sensor in the innate immune response to a herpesvirus (MCMV). [PubMed: 20351692]

106. Hertel L, et al. The interferon-inducible 204 gene, a member of the Ifi 200 family, is not involved in the antiviral state induction by IFN-alpha, but is required by the mouse cytomegalovirus for its replication. Virology. 1999; 262:1-8. [PubMed: 10489335]

107. Rehwinkel J, et al. RIG-I detects viral genomic RNA during negative-strand RNA virus infection. Cell. 2010; 140:397-408. [PubMed: 20144762]

108. Lee HK, Lund JM, Ramanathan B, Mizushima N, Iwasaki A. Autophagy-dependent viral recognition by plasmacytoid dendritic cells. Science. 2007; 315:1398-1401. [PubMed: 17272685]

109. Melchjorsen J, Paludan SR. Induction of RANTES/CCL5 by herpes simplex virus is regulated by nuclear factor kappa B and interferon regulatory factor 3. J Gen Virol. 2003; 84:2491-2495. [PubMed: 12917470]

110. Delboy MG, Roller DG, Nicola AV. Cellular proteasome activity facilitates herpes simplex virus entry at a postpenetration step. J Virol. 2008; 82:3381-3390. [PubMed: 18234803]

111. Soulat D, et al. The DEAD-box helicase DDX3X is a critical component of the TANK-binding kinase 1-dependent innate immune response. EMBO J. 2008; 27:2135-2146. [PubMed: 18583960]

112. Schroder M, Baran M, Bowie AG. Viral targeting of DEAD box protein 3 reveals its role in TBK1/IKKepsilon-mediated IRF activation. EMBO J. 2008; 27:2147-2157. [PubMed: 18636090]

113. Ishikawa H, Barber GN. STING is an endoplasmic reticulum adaptor that facilitates innate immune signalling. Nature. 2008; 455:674-678. The studies published in reference 107 and 108 identify and describe STING as an essential adaptor in intracellular DNA signaling, and reveal the importance of subcellular localization in innate immune recognition and signaling. [PubMed: 18724357]

114. Ishikawa H, Ma Z, Barber GN. STING regulates intracellular DNA-mediated, type I interferondependent innate immunity. Nature. 2009; 461:788-792. [PubMed: 19776740]

115. Saitoh T, et al. Atg9a controls dsDNA-driven dynamic translocation of STING and the innate immune response. Proc Natl Acad Sci U S A. 2009; 106:20842-20846. [PubMed: 19926846]

116. Smiley JR. Herpes simplex virus virion host shutoff protein: immune evasion mediated by a viral RNase? J Virol. 2004; 78:1063-1068. [PubMed: 14722261]

117. Kawai T, Akira S. Innate immune recognition of viral infection. Nat Immunol. 2006; 7:131-137. [PubMed: 16424890]

118. Abate DA, Watanabe S, Mocarski ES. Major human cytomegalovirus structural protein pp65 (ppUL83) prevents interferon response factor 3 activation in the interferon response. $J$ Virol. 2004; 78:10995-11006. [PubMed: 15452220]

119. Browne EP, Shenk T. Human cytomegalovirus UL83-coded pp65 virion protein inhibits antiviral gene expression in infected cells. Proc Natl Acad Sci U S A. 2003; 100:11439-11444. [PubMed: 12972646]

120. McGregor A, Liu F, Schleiss MR. Molecular, biological, and in vivo characterization of the guinea pig cytomegalovirus (CMV) homologs of the human CMV matrix proteins pp71 (UL82) and pp65 (UL83). J Virol. 2004; 78:9872-9889. [PubMed: 15331722]

121. Leib DA, et al. Interferons regulate the phenotype of wild-type and mutant herpes simplex viruses in vivo. J Exp Med. 1999; 189:663-672. [PubMed: 9989981] 
122. Saira K, Zhou Y, Jones C. The infected cell protein 0 encoded by bovine herpesvirus 1 (bICP0) induces degradation of interferon response factor 3 and, consequently, inhibits beta interferon promoter activity. J Virol. 2007; 81:3077-3086. [PubMed: 17215277]

123. Paladino P, Collins SE, Mossman KL. Cellular localization of the herpes simplex virus ICP0 protein dictates its ability to block IRF3-mediated innate immune responses. PLoS One. 2010; 5:e10428. [PubMed: 20454685]

124. Melroe GT, Silva L, Schaffer PA, Knipe DM. Recruitment of activated IRF-3 and CBP/p300 to herpes simplex virus ICP0 nuclear foci: Potential role in blocking IFN-beta induction. Virology. 2007; 360:305-321. [PubMed: 17126870]

125. Joo CH, et al. Inhibition of interferon regulatory factor 7 (IRF7)-mediated interferon signal transduction by the Kaposi's sarcoma-associated herpesvirus viral IRF homolog vIRF3. J Virol. 2007; 81:8282-8292. [PubMed: 17522209]

126. Wies E, et al. The Kaposi's Sarcoma-associated Herpesvirus-encoded vIRF-3 Inhibits Cellular IRF-5. J Biol Chem. 2009; 284:8525-8538. [PubMed: 19129183]

127. Donaghy H, et al. Role for plasmacytoid dendritic cells in the immune control of recurrent human herpes simplex virus infection. J Virol. 2009; 83:1952-1961. [PubMed: 19073735]

128. Sainz B Jr, Halford WP. Alpha/Beta interferon and gamma interferon synergize to inhibit the replication of herpes simplex virus type 1. J Virol. 2002; 76:11541-11550. [PubMed: 12388715]

129. Gargano LM, Moser JM, Speck SH. Role for MyD88 signaling in murine gammaherpesvirus 68 latency. J Virol. 2008; 82:3853-3863. [PubMed: 18256152]

130. Gregory SM, et al. Toll-like receptor signaling controls reactivation of KSHV from latency. Proc Natl Acad Sci U S A. 2009; 106:11725-11730. [PubMed: 19564611]

131. Gargano LM, Forrest JC, Speck SH. Signaling through Toll-like receptors induces murine gammaherpesvirus 68 reactivation in vivo. J Virol. 2009; 83:1474-1482. [PubMed: 19019960]

132. Kristensen H, et al. Extracellular 2'-5' Oligoadenylate Synthetase stimulates RNase Lindependent antiviral activity: a novel mechanism of virus-induced innate immunity. J Virol. 2010; 84:11898-11904. [PubMed: 20844035]

133. Haahr S, Hollsberg P. Multiple sclerosis is linked to Epstein-Barr virus infection. Rev Med Virol. 2006; 16:297-310. [PubMed: 16927411]

134. Toussirot E, Roudier J. Epstein-Barr virus in autoimmune diseases. Best Pract Res Clin Rheumatol. 2008; 22:883-896. [PubMed: 19028369]

135. Leadbetter EA, et al. Chromatin-IgG complexes activate B cells by dual engagement of IgM and Toll-like receptors. Nature. 2002; 416:603-607. [PubMed: 11948342]

136. Kimkong I, Avihingsanon Y, Hirankarn N. Expression profile of HIN200 in leukocytes and renal biopsy of SLE patients by real-time RT-PCR. Lupus. 2009; 18:1066-1072. [PubMed: 19762380]

137. Mondini M, et al. Role of the interferon-inducible gene IFI16 in the etiopathogenesis of systemic autoimmune disorders. Ann N Y Acad Sci. 2007; 1110:47-56. [PubMed: 17911419]

138. Casrouge A, et al. Herpes simplex virus encephalitis in human UNC-93B deficiency. Science. 2006; 314:308-312. [PubMed: 16973841]

139. Diego RP, et al. Human TRAF3 adaptor molecule deficiency leads to impaired Toll-like receptor 3 response and susceptibility to herpes simplex encephalitis. Immunity. 2010; 33:400-411. [PubMed: 20832341]

140. Ariza ME, Glaser R, Kaumaya PT, Jones C, Williams MV. The EBV-encoded dUTPase activates NF-kappa B through the TLR2 and MyD88-dependent signaling pathway. J Immunol. 2009; 182:851-859. [PubMed: 19124728]

\section{Glossary}

\section{Lytic infection}

Nat Rev Immunol. Author manuscript; available in PMC 2013 June 18.
Viral replication in host cells either causes cellular death and lysis (lytic infection) or is compatible with cell survival (persistent infection). 
Permissive cells

Latency

\section{Pathogen-associated molecular patterns}

\section{Cross-presentation}

Autophagy

Interferonstimulated genes

PYHIN (pyrin and HIN domaincontaining protein) family

Tegument

\section{Neurovirulence factor}
2' 5'oligoadenylate synthetase

Cells that support replication of a given virus. Permissiveness is often determined by expression of specific components in the cells and/or the ability of viruses to circumvent host defense mechanisms.

A state where viruses lie dormant in infected cells with no detectable virus replication. From the latent state viruses can become activated to initiate productive replication.

(PAMPs). Evolutionarily conserved molecular structures recognized by pattern recognition receptors. PAMPs are either specific for whole classes of pathogens or used by both microorganism and host but present in abnormal locations.

The ability of certain antigen-presenting cells (APCs) to load peptides that are derived from exogenous antigens onto MHC class I molecules. This property is atypical, because most cells exclusively present peptides from their endogenous proteins on MHC class I molecules. Cross-presentation is essential for the initiation of immune responses to viruses that do not infect APCs.

A catabolic process in which cells degrade cytosolic content, including organelles, through the lysosomal machinery.

Genes induced by interferons, through their ISRE gene promoter element, which binds the IFN-activated transcription factor ISGF3. A subgroup of ISGs is induced directly through PRRs, through transcription factors of the IRF family.

A family of proteins with both Pyrin and HIN domains. Pyrin domains mediate pyrin/pyrin homotypic interactions and stimulate signal transduction, while HIN domains bind DNA.

An amorphous layer of proteins, which lines the space between the lipid membrane and the nucleocapsid of herpesviruses. The tegument proteins generally support viral replication and evasion of immune responses.

A factor essential for the ability of a pathogen be pathogenic in the nervous system. HSV and rabies virus are neurovirulent viruses.

A family of IFN- and virus-inducible enzymes that catalyzes the formation 2', 5' oligomers of adenosine, to stimulate antiviral activities dependent and independent of RNase L.

\section{Biographies}

Søren R. Paludan

Søren R. Paludan is Professor in virology in the Department of Medical Microbiology and Immunology, Aarhus University, Denmark. His research is focused on the cellular and molecular mechanisms of innate immune recognition and activation during herpesvirus infections.

Andrew G. Bowie 
Andrew G. Bowie is an Associate Professor in Immunology in the School of Biochemistry and Immunology at Trinity College Dublin, Ireland. His primary research interest is innate immune signaling, with a particular focus on pattern recognition receptor sensing of viruses, and viral evasion and subversion of host immune responses.

Kristy A. Horan

Kristy A. Horan received her Ph.D. from Monash University, Australia. She is currently a postdoctoral fellow in the Department of Medical Microbiology and Immunology, Aarhus University, Denmark, where she is investigating the role of intracellular nucleic acid sensors in the innate immune response to herpes simplex virus infections.

Katherine A. Fitzgerald

Katherine A. Fitzgerald is an Associate Professor of Medicine at the University of Massachusetts Medical School, Worcester, MA, USA. Her research interests focus on the molecular mechanisms underlying the sensing of microbial pathogens and the role of innate immune signaling receptors and signaling pathways in microbial pathogenesis. 


\section{Box 1}

\section{The herpes virion and lytic replication cycle}

The herpes virion is composed of a dsDNA genome, which encodes about 100 transcripts; an icosahedron capsid composed of 162 capsomers, including four protein subunits; the tegument, an amorphous layer of proteins, which are released into the host cell following infection; a lipid membrane bilayer, derived from the producer cell transGolgi network; and glycoproteins (at least 11) that are embedded in the lipid bilayer.

Herpesviruses enter host cells either at the cell surface or via $\mathrm{pH}$-dependent endocytosis through a process involving a trio of glycoproteins that are conserved among all herpesviruses. The tegument proteins are then released into the cell and the capsid is transported to the nuclear membrane, where DNA is released into the nucleus. The viral replication process is initiated by the expression of immediate-early genes, which encode proteins that promote expression of viral genes and also exert innate immune evasion. This is followed by expression of the early proteins, which are responsible for replication of the viral DNA genome, and eventually late proteins, which include capsid, tegument and glycoproteins. The late protein products and the replicated DNA are assembled into progeny virions, which are released from the cell either by exocytosis through the transGolgi network or cell lysis. (see figure)

Establishment and maintenance of latency is a complex process involving many viral and cellular components. It is believed that suppression of immediate-early genes, by virusencoded microRNAs for example, have a central role in this process. The innate immune system can detect components of the herpesvirus particle (glycoproteins and DNA) or replication intermediates produced during productive infection (RNA structures). 


\section{Online features}

\section{Online summary}

- Herpesviruses are a large family of DNA viruses, eight of which are able to cause diseases in humans, particularly in children and immuno-compromised individuals. All herpesviruses have the capacity to cause lytic infection in permissive cells, and to establish latent/recurrent infections in other cell types.

- The innate immune system detects infections using germline-encoded pattern recognition receptors (PRR)s. Toll-like receptors (TLR)s are membrane-bound PRRs detecting microbes in extracellular and endosomal locations. TLR2, 3, and 9 are well described sensors of herpesvirus infections.

- In the cytoplasm, active innate immune surveillance takes place and is mediated by nucleus acid sensors. Herpesvirus infections are sensed by both RNA and DNA sensing systems and recent reports suggest a particularly important role for the cytosolic DNA-sensing AIM2-like receptor (ALR) family in intracellular detection of herpesviruses.

- Given the relatively slow replication cycle of herpesviruses and the establishment of life-long infections, these viruses are highly dependent on efficient immune evasion strategies. It is now known that herpesviruses evade all classes of PRRs (including ALRs) as well as the downstream signaling machinery.

- Innate immune defense against herpesviruses is highly dependent on the type I interferon system and natural killer cells. Model studies in mice and genetic data from human, have revealed essential roles for both TLRs and intracellular DNA sensors in mounting protective immune responses against herpesviruses. 

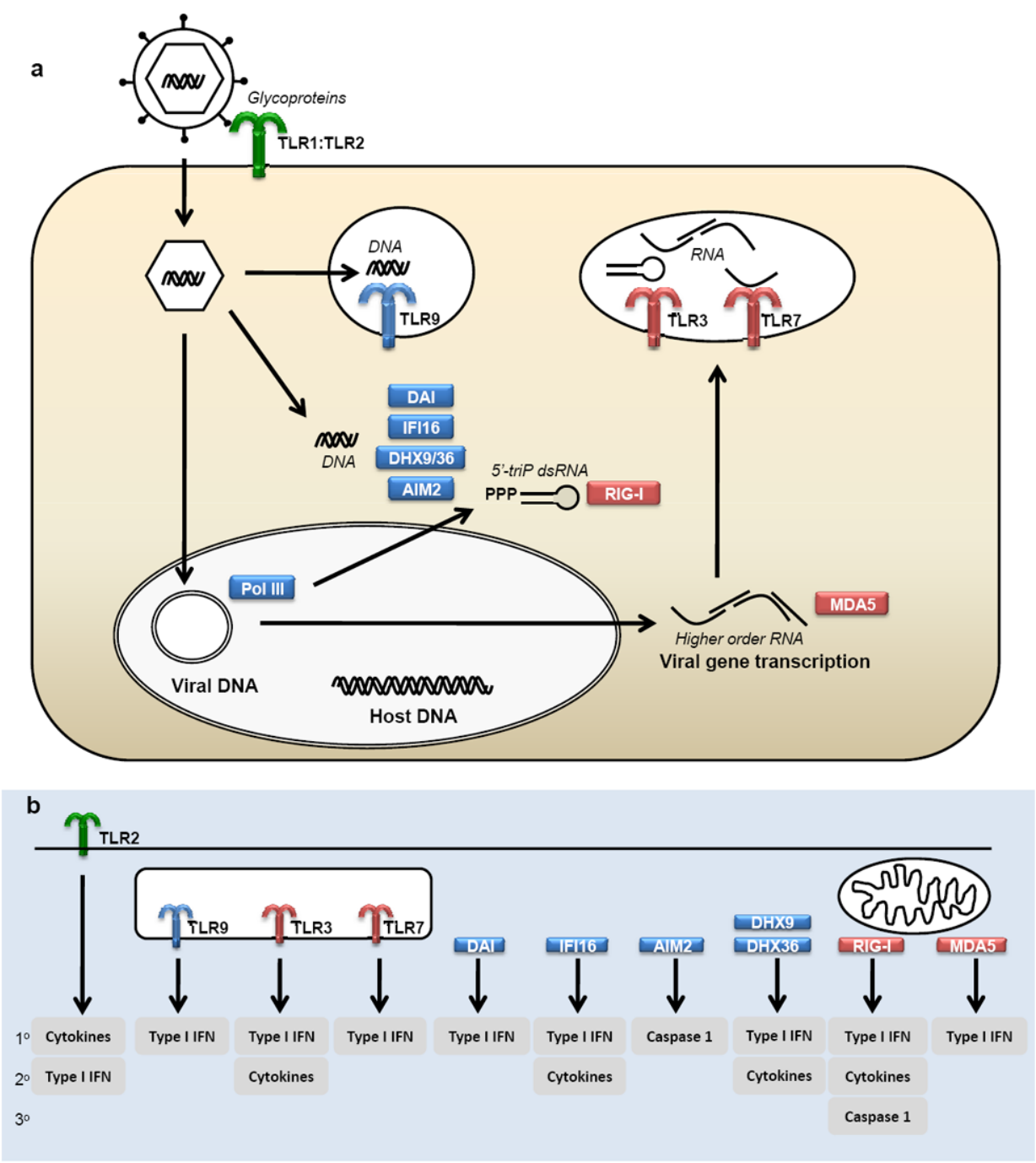

Figure 1. Innate immune recognition and activation by herpesviruses

a The virion is sensed by TLR2, which most likely detects herpesvirus glycoproteins and induces expression of pro-inflammatory cytokines and in specific cell types also type I IFNs. Viral genomic DNA is detected by TLR9 in endosomes, and by DAI, DHX9/36, AIM2, and IFI16 in the cytoplasm. DNA sensing by the Pol III/RIG-I system may take place in either the nucleus or the cytoplasm. b The intracellular DNA sensing pathways together lead to expression of both cytokines, type I IFNs, and activation of the inflammasome. Productive replication of herpesviruses leads to the accumulation of RNA species, including higher order RNA structures. These RNAs are sensed either in the cytoplasm by MDA5 or in endosomes by TLR3 and TLR7. The cellular response to RNA sensing involves the production of IFNs and cytokines. $1^{\circ}, 2^{\circ}, 3^{\circ}$, proposed relative importance of the downstream events activated by PRRs. AIM, absent in melanoma; DAI, DNA-dependent activator of interferon regulatory factors; DHX, DExD/H-box helicase; IFI; interferoninducible; IFN, interferon; MDA, melanoma differentiation-associated gene; RIG, retinoic acid inducible gene; TLR, Toll-like receptor. 


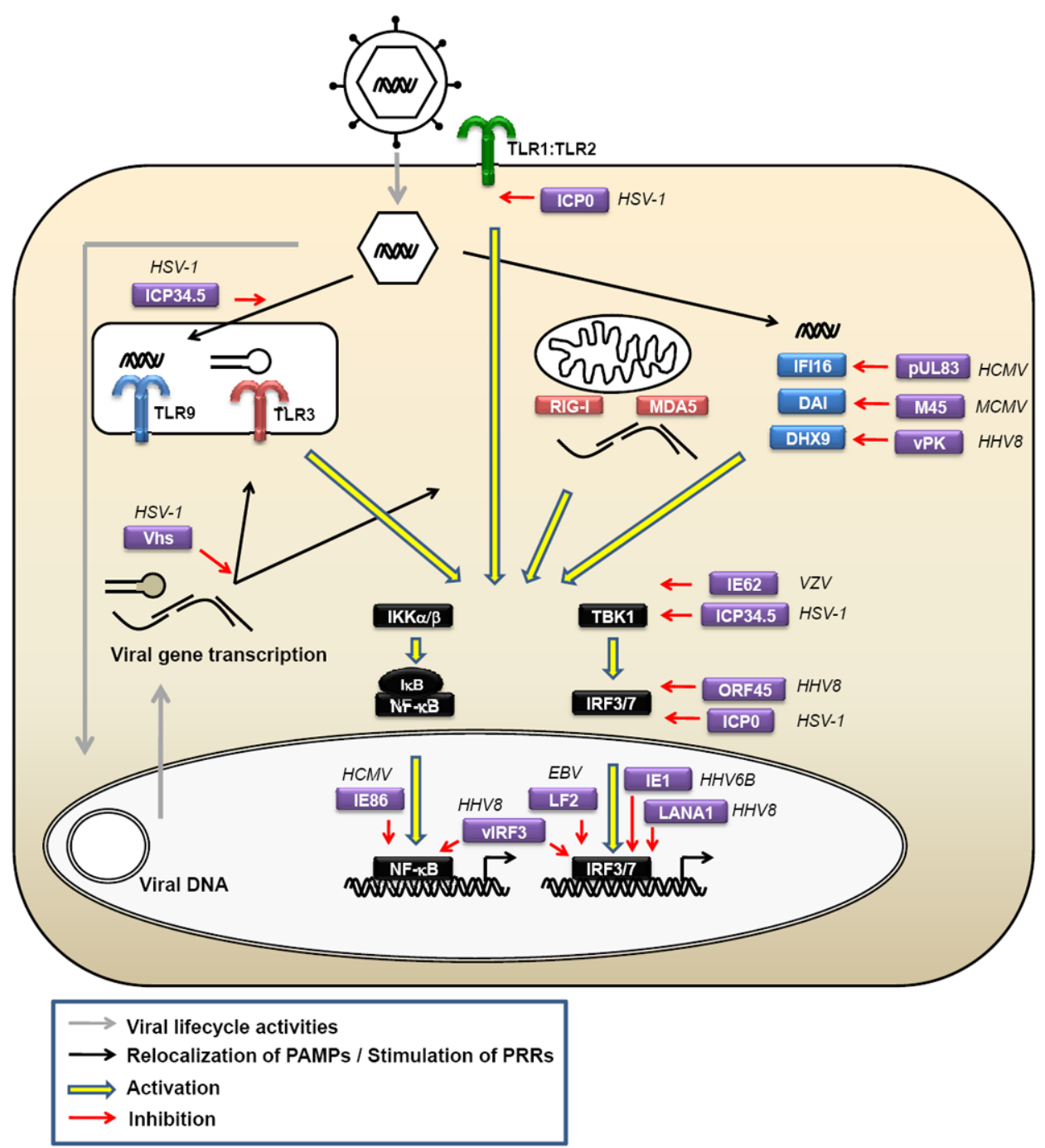

Figure 2. Intracellular detection of herpesvirus DNA and activation of signal transduction Productive replication of herpesviruses requires transport of the capsid to the nuclear pore, where the genomic DNA is released into the nucleus. Alternatively, herpesvirus DNA may be released from the capsid into the cytosol and be subject to immune recognition. Cytosolic sensors of viral capsids may exist, which target the capsid for degradation either through autophagy or the proteasome. Autophagy-mediated degradation of the capsid will expose the viral DNA to TLR9 in endosomes. Alternatively, TLR9 could receive the viral DNA from an endocytic or phagocytic route. Degradation of the capsid in the cytosol will expose the DNA for the cytosolic DNA sensors, including IFI16, and DAI, which in turn associates with STING and re-localizes from the ER to perinuclear vesicles from where signaling takes place. DHX9 and 36 detect cytosolic DNA and signal through MyD88 like TLR9. DAI, DNA-dependent activator of interferon regulatory factors; DDX3, DEAD box protein 3; DHX, aspartate-glutamate-any amino acid-aspartate/histidine (DExD/H)-box helicase; ER, endoplasmic reticulum; IFI, interferon $\gamma$-inducible; MyD88, myeloid differentiation primary-response protein 88 ; NF- $\mathrm{kB}$, nuclear factor $\mathrm{\kappa B}$; STING, stimulator of interferon genes; TBK, TANK-binding kinase 1;TLR, Toll-like receptor 


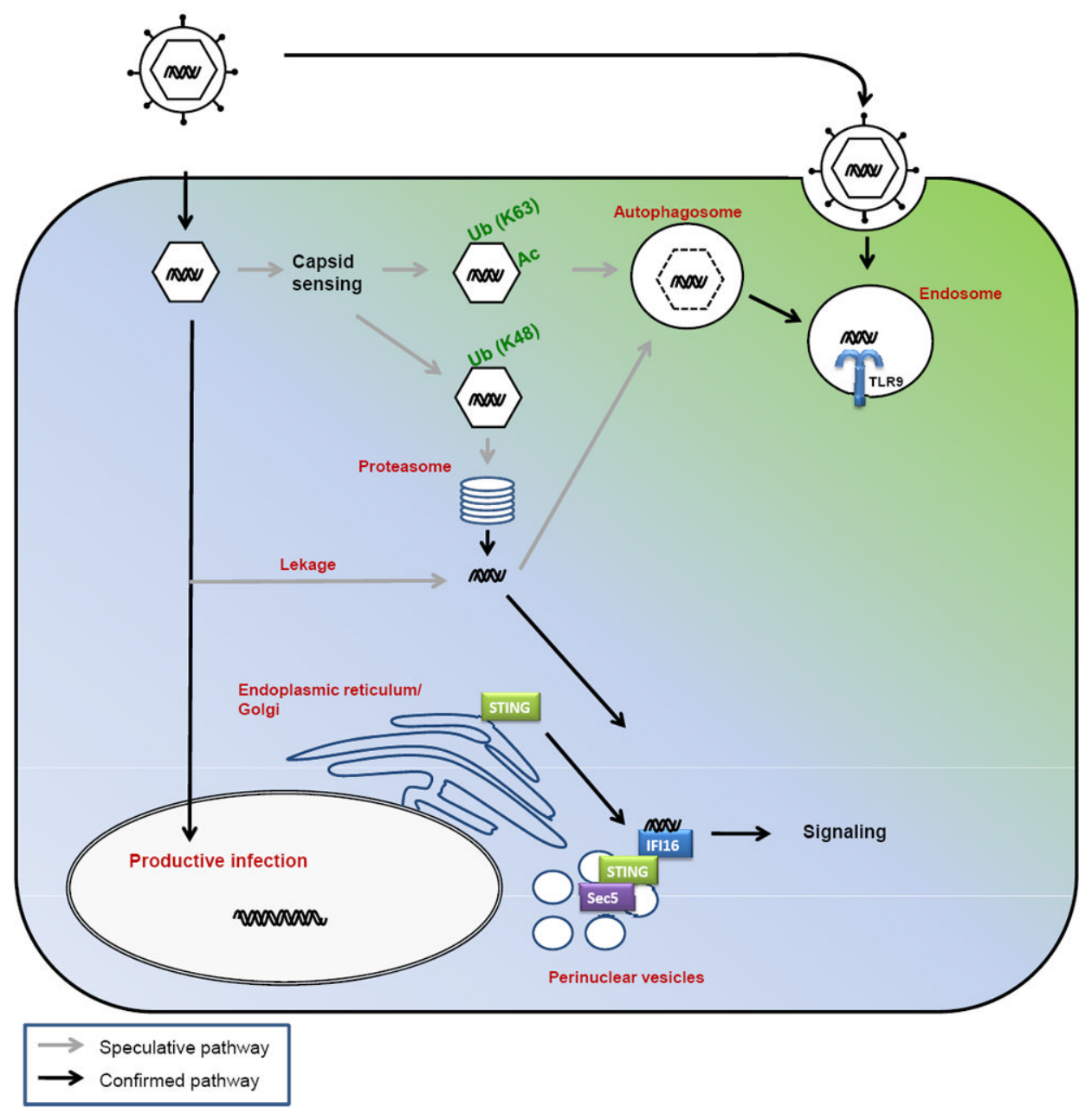

Figure 3. Evasion of PRR-mediated recognition, signalling and gene expression by herpesviruses The HSV proteins ICP34.5 and Vhs prevent the recognition of viral nucleic acids by inhibiting autophagy and degrading viral RNA, respectively. Herpesviruses inhibit signaling through both PRR-specific mechanisms (HSV-1 ICP0 inhibits TLR2 signalling by stimulating degradation of TLR adaptor molecules, and MCMV M45 inhibits recruitment or RIP1 to DAI) and more general mechanisms targeting all PRRs (for example, HHV8 ORF45 interacts with IRF7 and inhibits phosphorylation and nuclear translocation). Finally, several herpesvirus-encoded proteins (such as HHV8 vIRF3) inhibit transcription by interacting with NF- $\mathrm{KB}$ and IRF3 and/or IRF7 in the nucleus, hence preventing interaction with DNA and assembly of functional transcriptional complexes. CMV, cytomegalovirus; DAI, DNAdependent activator of interferon regulatory factors; HHV, human herpesvirus; ICP, infected cell protein; IRF, interferon regulatory factor; NF, nuclear factor; ORF, open reading frame; $\mathrm{PRR}$, pattern recognition receptor; RIP, receptor-interacting protein kinase; TLR, Toll-like receptor; Vhs, virion host shut-off. 


\section{Table 2}

PRRs and PAMPs in herpesviruses recognition and innate immune activation

\begin{tabular}{lllc}
\hline PRR & Virus & Proposed PAMP & Reference \\
\hline TLR2 & HSV-1, HSV-2 & Virion component & 49,50 \\
& VZV & Virion component & 51 \\
& HCMV & gB and/or gH & 47 \\
TLR3 & EBV & Virion component, dUTPase & 52,140 \\
& HSV-1 & dsRNA & 86 \\
& MCMV & dsRNA & 65 \\
TLR7 & EBV & EBER RNA & 81 \\
TLR9 & MCMV & ssRNA & 76 \\
& HSV-1, HSV-2 & Genomic DNA & 60,61 \\
& MCMV, HCMV & Genomic DNA & $62,65,66$ \\
MDA5 & EBV & Genomic DNA & 63,64 \\
Pol III / RIG-I & HSV-1 & Replication intermediate & 94 \\
& EBV & EBER DNA & 20 \\
DAI & HSV-1 & Genomic DNA & 19 \\
& HCMV & Genomic DNA & 14 \\
IFI16 & HSV-1 & Genomic DNA & 99 \\
DHX9/36 & HSV & Genomic DNA & 22 \\
\hline & MCMV & Genomic DNA & 102 \\
\hline
\end{tabular}

AIM, absent in melanoma; DAI, DNA-dependent activator of interferon regulatory factors; DHX, DExD/H-box helicase; dsRNA, double-stranded RNA; EBV, Epstein-Barr virus; gB, glycoprotein; HCMV, human cytomegalovirus; HHV, human herpesvirus; HSV, herpes simplex virus; IFI, interferon inducible; MDA, melanoma differentiation-associated gene; RIG, Retinoic acid inducible gene; TLR, Toll-like receptor; VZV, Varicella zoster virus. 